\title{
Role of Oxidative Stress in the Pathogenesis of OCD
}

\section{Madhura TK*}

Department of Biochemistry, Defense Institute of Advanced Technology, Near Khadakwasla Dam, Girinagar, Pune, India

\begin{abstract}
Oxidative stress is caused by an imbalance between the production of reactive oxygen and a biological system's ability to readily detoxify the reactive intermediates or easily repair the resulting damage. A particularly destructive aspect of oxidative stress is the production of reactive oxygen species, which include free radicals and peroxides. Oxidative stress is one of the mechanisms involved in neuronal damage induced by free radicals which causes membrane lipid degradation which occurs due to interaction of polyunsaturated fatty acids (PUFA). These free radicals cause catalytic destruction of membranes and likely damage vital functions of cell. Oxygen radicals are continuously produced intracellularly by oxidation- reduction reactions. MDA (malondialdehyde) is a product of lipid peroxidation. Oxidative damage of neuronal membrane causes increased MDA levels and impaired activity of SERT.
\end{abstract}

Keywords: Obsessive compulsive disorder; Serotonin; Malondialdehyde; Reduced glutathione; Free radicals

\section{Introduction}

Obsessions are defined as recurrent, persistent, thoughts, images or impulses that are experienced as intrusive \& inappropriate. Compulsions are repetitive behaviours or mental acts that the person feels driven to perform in response to an obsession or according to rigid rules [1].

Until the 1850s, obsessive-compulsive phenomena were considered to be a variant of the old notion of insanity. After 1860, organic causal hypotheses for OCD included dysfunctions of the autonomic nervous system and cortical blood supply. In 1880 OCD was included in the spectrum of neuroses. Psychological hypotheses suggested the OCD might result from volitional, intellectual, or emotional impairment, the last of which predominated after 1890 [2]. First description of OCD in childhood was given by Pierre Janet in 1903 who reported on a five year old boy with characteristic symptoms. OCD usually begins in adolescence or early adulthood although it can begin in childhood. Nearly $65 \%$ of the patients have the onset before 25 years of age and $<15 \%$ have onset after 35 years of age [3] (Table 1).

\section{Serotonin (5- Hydroxy Tryptamine)}

It's a monoamine neurotransmitter. Biochemically derived from tryptophan, serotonin is primarily found in the gastrointestinal (GI)

\begin{tabular}{|l|c|}
\hline Obsessions & $\%$ \\
\hline Fear of contamination & 61 \\
\hline Aggressive thoughts, images and impulses & 43 \\
\hline Need for symmetry & 35 \\
\hline Sexual & 31 \\
\hline Religion & 30 \\
\hline Pathological doubt & 21 \\
\hline Miscellaneous & 40 \\
\hline Compulsions & $\%$ \\
\hline Cleaning and washing & 50 \\
\hline Ordering & 41 \\
\hline Repeating & 38 \\
\hline Checking & 18 \\
\hline Hoarding & 7 \\
\hline Miscellaneous & 41 \\
\hline
\end{tabular}

Table 1: The following are the common obsessive - compulsive symptoms. tract, platelets, and in the central nervous system (CNS).Functions of serotonin include the regulation of mood, appetite, sleep, cognitive functions, including memory and learning [4,5] (Figure 1).

Serotonin is the major neurotransmitter in raphe nuclei, which are grouped into nine pairs and distributed along the brainstem, centered around the reticular formation. Axons of neurons in the "caudal" raphe nuclei terminate at deep cerebellar nuclei, cerebellar cortex, spinal cord (Figure 2).

Serotonin is released at terminal synaptic boutons acting at a wide gap of $>20 \mu \mathrm{m}$ synapse and acts to activate 5-HT receptors located on

\section{Tryptophan}

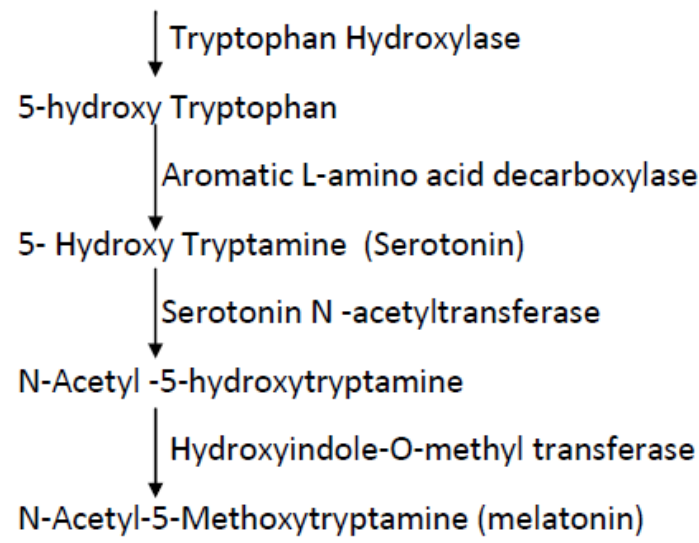

Figure 1: Flow chart shows the Biosynthesis of serotonin and metabolism of serotonin to melatonin.

*Corresponding author: Madhura TK, Defense Institute of Advanced Technology, Near Khadakwasla dam, Girinagar, Pune 411025, India, Tel: 9921041635; E-mail: madhuratksharma@gmail.com

Received: September 18, 2015; Accepted: October 13, 2015; Published October 16, 2015

Citation: Madhura TK (2015) Role of Oxidative Stress in the Pathogenesis of OCD. Biochem Anal Biochem 4: 217. doi:10.4172/2161-1009.1000219

Copyright: (c) 2015 Madhura TK. This is an open-access article distributed under the terms of the Creative Commons Attribution License, which permits unrestricted use, distribution, and reproduction in any medium, provided the original author and source are credited. 


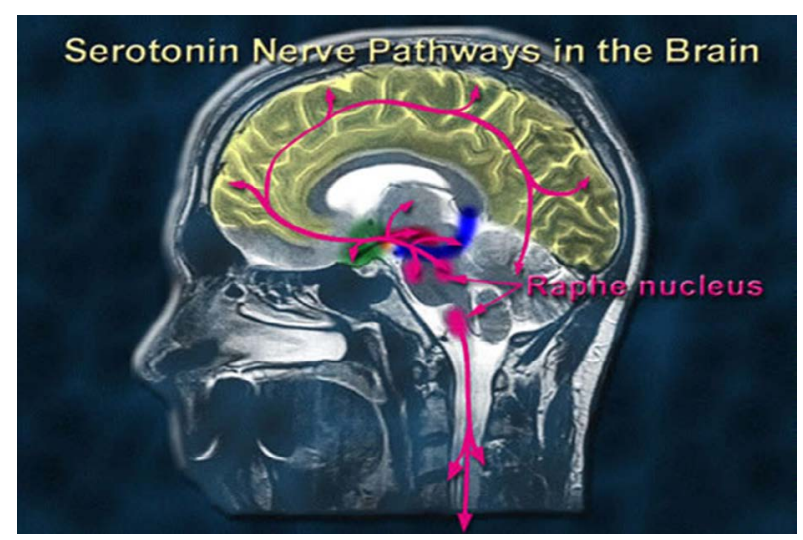

Figure 2: Serotonin Nerve Pathways in the Brain.

the dendrites, cell bodies and presynaptic terminals of adjacent neurons. Serotonin receptors are $\mathrm{G}$ protein coupled seven transmembrane (or "heptahelical") receptors that activate an intracellular second messenger cascade except 5-HT3, which is liagand gated ion channel [6].

SERT spans the plasma membrane 12 times. It belongs to NE, DA, SERT monoamine transporter family. Transporters are important sites for agents that treat psychiatric disorders. Both drugs that reduce the binding of serotonin to transporters (selective serotonin reuptake inhibitors, or SSRIs) and, less often, that increase it (selective serotonin reuptake enhancers, or SSREs) are used to treat mental disorders. About half of patients with OCD are treated with SSRIs. Fluoxetine is an example of a selective serotonin reuptake inhibitor, and tianeptine is an example of a selective serotonin reuptake enhancer. The highly evolutionarily conserved serotonin transporter (SERT) regulates the entire serotonergic system and its receptors via modulation of extracellular fluid serotonin concentrations [7].

The gene that encodes the serotonin transporter is called solute carrier family 6, member 4 (SLC6A4). In humans the gene is found on chromosome 17 on location 17q11.1-q12.

\section{Free Radical Biochemistry}

Free radicals are highly reactive molecular species with an unpaired electron; that persist for only a short time of the order of $10^{-9}$ to $10^{-12}$ seconds before they collide with another molecule and either abstract or donate an electron in order to achieve stability. In doing so, they generate a new radical from the molecule with which they collided.

An atom is composed of central nucleus with pairs of electrons orbiting around it. Each electron in a pair has an opposite intrinsic angular momentum. Some atoms and molecules have unpaired electrons and these are called free radicals. Free radicals are usually unstable and highly reactive because the unpaired electrons tend to form pairs with other electrons. Free radicals are result of normal cellular metabolism.

\section{Generation of Oxygen Free Radicals}

\section{Electron leakage}

Major source of free radicals is due to 'electron leakage' from electron transport chain. Normally efficiency on electron transfer recations is so high that most of oxygen is completely reduced to form water and $<2 \%$ forms oxygen free radicals.

\section{Normal oxidation reduction reactions}

Generation of free radicals is common during normal metabolism. Examples:

- Autooxidation of certain compounds

Adrenaline, thiols, ascorbic acid

- $\quad$ Flavin coenzymes present in peroxisomes (Figure 3).

- Enzymes like xanthine oxidase, aldehyde oxidase and dihydro-orotate dehydrogenase can also generate oxygen free radicals [8].

\section{Exogenous agents}

Toxic compounds like carbontetrachloride, exposure to ionizing radiation damages tissues by producing free radicals. Cigarette smoking, alcohol, pollution produce immense high concentration of free radicals. Drugs propafenone, amiodarone are known to produce ROS.

\section{Respiratory burst}

Deliberate production of free radicals by the phagocytes with the purpose of destroying pathogens. The most damaging free radicals in biological systems are oxygen radicals especially superoxide $\left(\mathrm{O}_{2} \cdot\right.$ ), hydroxyl $(\mathrm{OH} \cdot)$ and perhydroxyl $\left(\mathrm{O}_{2} \mathrm{H} \cdot\right)$, hydroperoxy (HOO-), peroxyl (ROO). $\mathrm{H}_{2} \mathrm{O}_{2}$ (hydrogen peroxide), hypochlorous acid (HOCL), $\mathrm{O}_{3}$ (ozone), $\mathrm{O}_{2}$ (singulate oxygen) are non radicals (Figure 4).

\section{Lipid Peroxidation}

Refers to the oxidative degradation of lipids. It is the process in which free radicals "steal" electrons from the lipids in cell membranes,

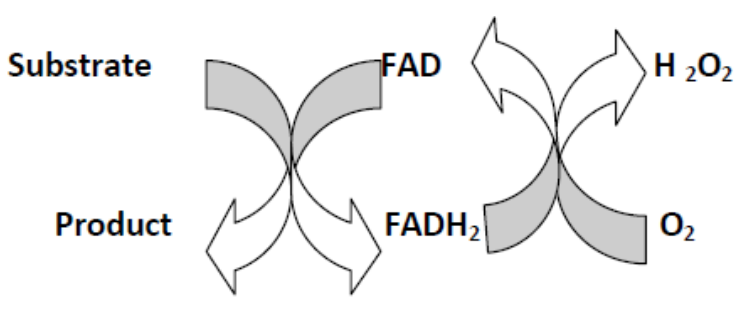

Figure 3: Flavin coenzymes present in peroxisomes.

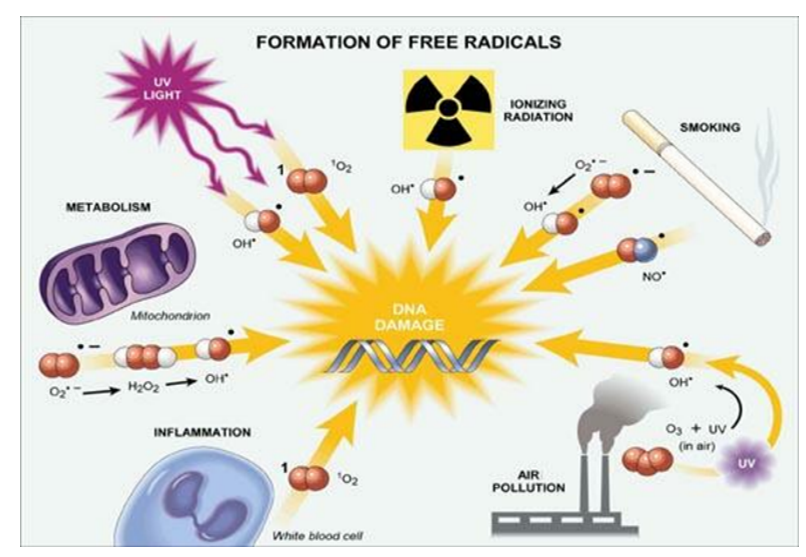

Figure 4: Formationof Free Radicals. 
resulting in cell damage. This process proceeds by a free radical chain reaction mechanism. It most often affects polyunsaturated fatty acids, because they contain multiple double bonds in between which lie methylene bridges $\left(-\mathrm{CH}_{2}-\right)$ that possess especially reactive hydrogens. As with any radical reaction, the reaction consists of three major steps: initiation, propagation, and termination.

\section{Initiation}

Initiation is the step in which a fatty acid radical is produced. The most notable initiators in living cells are reactive oxygen species (ROS), such as $\mathrm{OH}$. and $\left[\mathrm{HO}_{2}\right]$, which combines with a hydrogen atom to make water and a fatty acid radical.

\section{Propagation}

The fatty acid radical is not a very stable molecule, so it reacts readily with molecular oxygen, thereby creating a peroxyl-fatty acid radical. This radical is also an unstable species that reacts with another free fatty acid, producing a different fatty acid radical and lipid peroxide, or cyclic peroxide if it had reacted with itself. This cycle continues, as the new fatty acid radical reacts in the same way.

\section{Termination}

When a radical reacts with a non-radical, it always produces another radical, which is why the process is called a "chain reaction mechanism". The radical reaction stops when two radicals react and produce a nonradical species. This happens only when the concentration of radical species is high enough for there to be a high probability of collision of two radicals. Living organisms have different molecules that speed up termination by catching free radicals and, therefore, protecting the cell membrane. One important such antioxidant is vitamin E. Other anti-oxidants made within the body include the enzymes superoxide dismutase, catalase, and peroxidase (Figure 5).

\section{Malondialdehyde (MDA)}

Malondialdehyde or malonaldehyde can be formed during lipid peroxidation of polyunsaturated fatty acids (PUFA), as explained previously under the heading of 'Lipid peroxidation'. MDA is ubiquitous compound produced in substantial quantity in mammalian tissues both as an end product of unsaturated lipid peroxidation and as a side product of prostaglandin and thromboxane biosynthesis. it is also produced by $\gamma$ - irradiation of carbohydrates $[9,10]$.

\section{Under physiological conditions pH 7.4}

MDA exists as an enolate anion $(\mathrm{O}-\mathrm{CH}=\mathrm{CH}-\mathrm{CHO})$, a form that

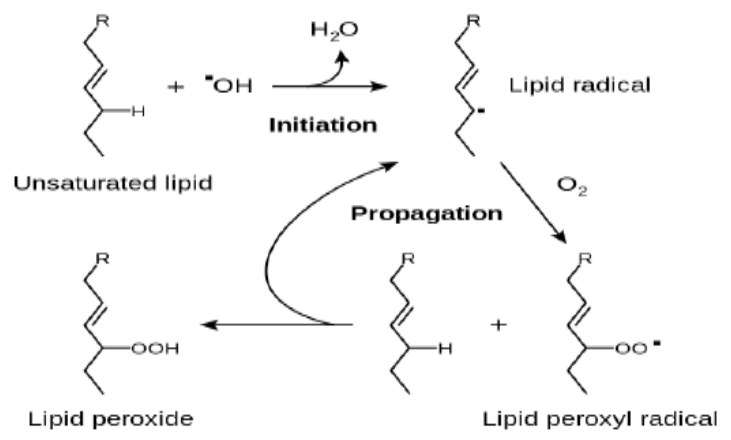

Figure 5: Chain reaction mechanism.

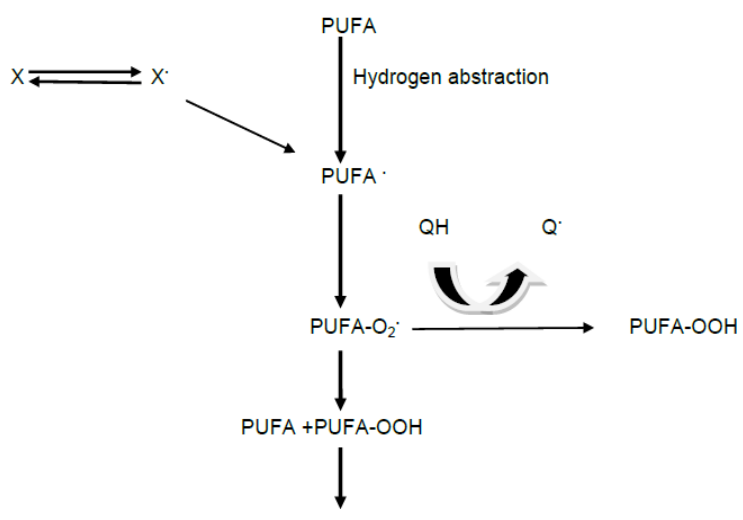

Figure 6: Flowchart shows scheme of lipid peroxidation.

is only fairly reactive, forming Schiff bases with molecules containing a free amine group.

Under more acidic conditions ( $\mathrm{pH}<4$ ), however, $ß$-hydroxyacrolein ( $\mathrm{HO}-\mathrm{CH}=\mathrm{CH}-\mathrm{CHO}$ ) ( $\mathrm{BHA})$ is the pre-dominant form. Unfortunately, $B \mathrm{HA}$ is a very reactive electrophile capable of reacting in a Michael addition with a number of biologically important nucleophiles (e.g.,thiols). Proteins are much more reactive with MDA than free amino acids forming a variety of adducts and cross-links. MDA can also react with DNA bases producing a variety of mutagenic compounds. Further- more, MDA has the potential to induce aminoimino-propen cross-links between complimentary strands of DNA and can also cause the formation of DNA-protein cross links.

MDA has been reported to be toxic, carcinogenic and mutagenic. It reacts with DNA to form adducts to deoxyguanosine and deoxyadenosine [11-14] (Figure 6).

\section{Reduced Glutathione}

It's a water soluble linear tripeptide composed of glutamine, cysteine, and glycine. Referred to as body's master antioxidant. Technically N-L-gamma-glutamyl-cysteinyl glycine or L-glutathione, the molecule has a sulfhydryl $(\mathrm{SH})$ group on the cysteinyl portion, which accounts for its strong electron-donating character. Cysteine is the rate-limiting factor in cellular glutathione synthesis, since this amino acid is relatively rare in food stuffsIt is virtually present in every cell of the body. The highest concentration of glutathione is in the liver, making it critical in the body's detoxification process [15] (Figure 7).

\section{Synthesis of Glutathione}

Cells make Glutathione in two adenosine triphosphate (ATP) dependent steps:

First, gamma-glutamylcysteine is synthesized from L-glutamate and cysteine via the enzyme gamma-glutamylcysteine synthetase (glutamate cysteine ligase, GCL). This reaction is the rate-limiting step in glutathione synthesis.

Second, glycine is added to the C-terminal of gammaglutamylcysteine via the enzyme glutathione synthetase (Figures 8 and 9).

\section{Glutathione - Its Multiple Functions}

- It is the major endogenous antioxidant produced by the cells, participating directly in the neutralization of free radicals and reactive 
glutathione (GSH)<smiles>COC(=O)C(N)CCC(=O)NC(CS)C(=O)NNCC(=O)[O-]</smiles>

Figure 7: Reduced Glutathione.

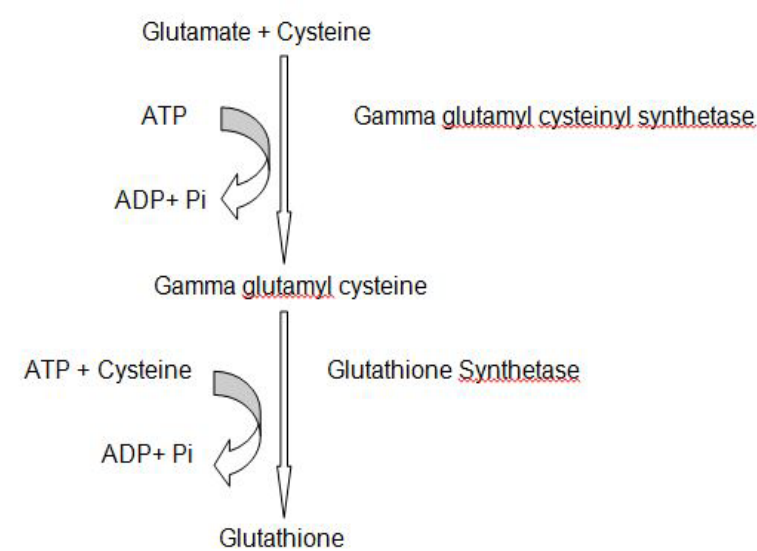

Figure 8: Synthesis of Glutathione.

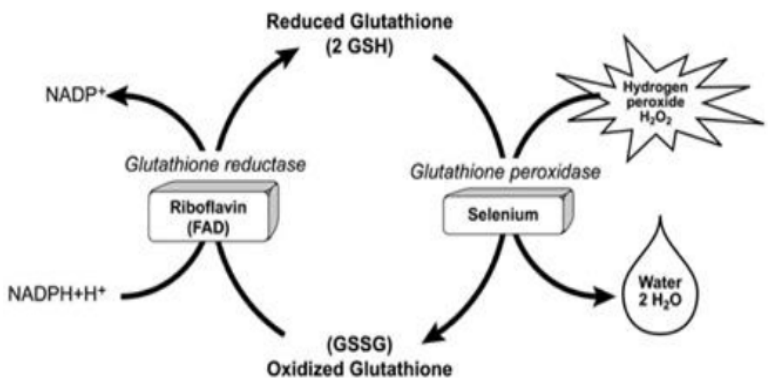

Figure 9: Glutathione recycling is as follows

oxygen compounds, as well as maintaining exogenous antioxidants such as vitamins $\mathrm{C}$ and $\mathrm{E}$ in their reduced (active) forms [16].

- Regulation of the nitric oxide cycle, which is critical for life but can be problematic if unregulated [17].

- It is used in metabolic and biochemical reactions such as DNA synthesis and repair, protein synthesis, prostaglandin synthesis, amino acid transport, and enzyme activation. Thus, every system in the body can be affected by the state of the glutathione system, especially the immune system, the nervous system, the gastrointestinal system and the lungs.

- It has a vital function in iron metabolism. Yeast cells depleted of or containing toxic levels of GSH show an intense iron starvation-like response and impairment of the activity of extra-mitochondrial ISC enzymes, followed by death [18].
- Glutathione (GSH) participates in leukotriene synthesis and is a cofactor for the enzyme glutathione peroxidase. It is also important as a hydrophilic molecule that is added to lipophilic toxins and waste in the liver during biotransformation before they can become part of the bile. Glutathione is also needed for the detoxification of methylglyoxal, a toxin produced as a by-product of metabolism.

\section{Materials and Methods}

This is a case control study. Ethical affirmations are as follows

Volunteered Research participants: 30 cases of obsessive compulsive disorder and 30 controls (age \& sex matched)

- The study has ensured quality and integrity of research.

- I have taken proper informed consent in the language understandable by the patients after explaining the purpose of study and the concept behind the study and risk involved.

- I have maintained the respect, confidentiality and anonymity of my research participants.

- It has been ensured that participants will involve in my study voluntarily and no decisions had been forced upon them.

- I has avoided harm to the participants to the best possible extent; and

- I claim that my research is independent and impartial.

After obtaining informed consent, 30 cases of clinically diagnosed with OBSESSIVE COMPULSIVE DISORDER attending psychiatry OPD were enrolled in the study. Age and sex matched thirty normal individuals were studied as controls. Under all aseptic precautions, 5 $\mathrm{ml}$ of venous blood was drawn through phlebotomy using disposable syringe. This sample was distributed in two different vacuitainers: 4 $\mathrm{ml}$ in plain vacuitainer and allowed to clot and $1 \mathrm{ml}$ in EDTA coated vacuitainer. After one hour, serum was separated by centrifuging at $2500 \mathrm{rpm}$ for $5 \mathrm{~min}$ at room temperature. Separated serum should be free from hemolysis and turbidity.

\section{Estimation of Serum MDA Level}

\section{Thiobarbituric acid method for MDA estimation}

Serum sample with lipid peroxide is first treated with trichloroacetic acid (TCA) for protein precipitation and then treated with $0.67 \%$ thiobarbituric acid (TBA). The mixture is treated for 10 minutes is boiling water bath. One molecule of MDA reacts with two molecules of TBA. The resulting chromogenic adduct is centrifuged and the intensity of color developed in supernatant is measured colorimetrically at 530 $\mathrm{nm}$. MDA levels are expressed in nanomol $/ \mathrm{ml}$; $(\mathrm{nmol} / \mathrm{mL})$; normal range $2-5 \mathrm{nmol} / \mathrm{mL}$.

\section{Reagents}

\section{A. 40\% TCA (trichloroacetic acid) \\ 40 gram of TCA in $100 \mathrm{ml}$ of distilled water. \\ B. $0.67 \%$ TBA (Thiobarbituric acid)}

Dissolve $670 \mathrm{mg}$ of TBA in $100 \mathrm{ml}$ of distilled water in boiling water bath. Prepare this reagent freshly.

\section{Stock standard MDA (malondialdehyde)}

Stock MDA is prepared from 1,1,3,3, tetraethoxypropane 
by acid hydrolysis. A solution containing $0.5 \mathrm{mmol}$ of $1,1,3,3$, tetraethoxypropane in $50 \mathrm{ml}$ distilled water and $0.5 \mathrm{ml} 0.1 \mathrm{~m} \mathrm{HCL}$. Is warmed at 50 degree centigrade for 1 hour and the volume adjusted to $100 \mathrm{ml}$ with diatilled water. The concentration of free MDA was determined spectrophotometrically at $267 \mathrm{~nm}$ using a molar absorption coefficient of 31800 (Table 2).

Mix well and keep the tubes in boiling water bath for ten minutes. cool at room temperature. Centrifuge at $1500 \mathrm{rpm}$ for 5 minutes. Pipette the supernatant and read at $530 \mathrm{~nm}$. The unknown test concentration were plotted for standardization graph.

\section{Method for the Determination of Reduced Glutathione Concentration}

\section{Principle}

Virtually all the non-protein sulphydryl groups of RBC's are in the form of reduced GSH. 5',5' DTNB is a disulphide chromogen that is readily reduced by sulphydryl compounds to an intensely yellow compound. The absorbance of the reduced chromogen is measured at $412 \mathrm{~nm}$ and is directly proportional to the GSH concentration. Estimation of reduced glutathione (GSH) done using DTNB reagent and analyzed within 24 hours of sample collection. Blood levels of GSH expressed in $\mathrm{mg} / \mathrm{dL}$. Normal range $17-39 \mathrm{mg} / \mathrm{dL}$.

\section{Specimen collection}

Whole blood $(3 \mathrm{ml})$ anticoagulated with EDTA.

Included are normal control sample specimen with each assay.

\section{Reagents}

\section{Precipitating solution}

1.67 gm glacial metaphospheric acid +0.20 gm disodium or dipotassium EDTA $+30 \mathrm{gm} \mathrm{NaCl}$ per $100 \mathrm{ml}$ of distilled water

(solution is stable for approximately $3 \mathrm{wk}$ at 4 degree centigrade, stored in deep freezer )

\section{Phosphate solution}

$0.3 \mathrm{M} \mathrm{Na}_{2} \mathrm{HPO}_{4}$ prepared in distilled water (42.59 $\mathrm{gm}$ of $\mathrm{Na}_{2} \mathrm{HPO}_{4}$ in $1000 \mathrm{ml} \mathrm{DW}$ ) stable indefinitely at 4 degree centigrade

\section{DTNB reagent (55' Dithiobis - 2 nitrobenzoic acid)}

$40 \mathrm{mg}$ of DTNB per $100 \mathrm{ml}$ of $1 \%$ sodium citrate solution (1 gm of sodium citrate in $100 \mathrm{ml} \mathrm{DW}$ ) stored in deep freezer stable for 13 weeks at 4 degree centigrade.

\section{GSH calibrators}

$100 \mathrm{mg}$ GSH in a $100 \mathrm{ml}$ volumetric flask and bring to volume with reagent grade water. Invert repeatedly until GSH is completely dissolved.

Prepare 50 and $10 \mathrm{mg} / \mathrm{dl}$ calibrators.

\begin{tabular}{|c|c|c|c|}
\hline SI no. & Reagents & Test & Blank \\
\hline $\mathbf{1}$ & Serum & $1.0 \mathrm{ml}$ & --- \\
\hline $\mathbf{2}$ & Distilled water & ---- & $1.0 \mathrm{ml}$ \\
\hline $\mathbf{3}$ & $40 \%$ TCA & $1.0 \mathrm{ml}$ & $1.0 \mathrm{ml}$ \\
\hline $\mathbf{4}$ & TBA $(0.67 \%)$ & $2.0 \mathrm{ml}$ & $2.0 \mathrm{ml}$ \\
\hline
\end{tabular}

Table 2: Reagents

\begin{tabular}{|c|c|c|c|}
\hline & Reagents & Blank & Assay \\
\hline A & Filterate & -- & 2.0 \\
\hline B & Precipitating reagent & 1.2 & -- \\
\hline C & DW & 0.8 & -- \\
\hline D & $\mathrm{NaH}_{2} \mathrm{PO}_{4}$ solution & 8.0 & 8.0 \\
\hline E & DTNB solution & 1.0 & 1.0 \\
\hline
\end{tabular}

Table 3: Preparation cuvettes.

$50 \mathrm{mg} / \mathrm{dl}: 5 \mathrm{ml}$ of stock solution $+5 \mathrm{ml} \mathrm{DW}$

$10 \mathrm{mg} / \mathrm{dl}: 5 \mathrm{ml}$ of stock solution $+45 \mathrm{ml}$ of DW

GSH calibrator are not stable and must be freshly prepared.

\section{Procedure}

1. Place $0.2 \mathrm{ml}$ of whole blood into $10 \mathrm{ml}$ test tube. Add $1.8 \mathrm{ml}$ of $\mathrm{DW}$, mix to hemolyse

2. Promptly add $3.0 \mathrm{ml}$ of precipitating solution, mix.

3. Allow to stand for 5 minute at room temperature and filter through coarse grade filter paper.

4. Prepare cuvettes as follows (Table 3 ).

5. Cap cuvette and inverts three times to mix.

6. Read absorbance at $412 \mathrm{~nm}$ within 4 min of preparing cuvette.

7. Assay GSH calibrators, omitting filtration step.

8. Prepare a calibrator curve. Determine the GSH concentration of whole blood specimen form the graph.

9. Calculate the GSH concentration.

Normal range: $17-39 \mathrm{mg} / \mathrm{d}$

\section{Observations and Discussion}

Recent studies have shown that oxidative stress play a vital role in pathophysiology of OCD and symptomatic precipitation during acute attack and even its improvement with supplementation of antioxidants like Vitamin C.The reason why oxidative stress is increased in patients with OCD is still unclear. Patients with OCD do precipitate with symptoms during acute attack of anxiety and stress. Anxiety may cause secretion of catecholamines which in turn may lead to free radical production through NADPH oxidase. Oxidative stress thus developed causes peroxidation of membrane lipids, hence further increasing the symptoms of OCD. Lipid peroxidation releases excess malondialdehyde into blood. Body defense mechanism against free radical injury causes exhaustion of endogenous antioxidants, which depicted in our study with lowered levels of reduced glutathione. From the above facts it is clear that malondialdehyde play a role in pathogenesis of OCD and can be a good marker. So, in the present study an attempt was made to find out the efficacy of malondialdehyde as a marker in patients of obsessive compulsive disorder. We have also compared blood levels of reduced glutathione (GSH) as a marker of antioxidant status in the body.

Free radicals are extremely reactive molecular species with an unpaired electron in its outer most orbit; that persist for only a short period of $10^{-9}$ to $10^{-12}$ seconds. Therefore they are difficult to measure directly. Many studies have used an indirect approach to demonstrate free radical reaction with other molecules, such as DNA, lipids or proteins or the levels of antioxidant, according to the hypothesis that their changes are a consequence of the reaction with radicals. When 
free radicals overcome the cellular antioxidant defenses oxidative stress takes place potentially leading to damage of all the principal cellular molecules. The brain is especially prone to free radical damage for following reasons:

- It is very rich in polyunsaturated fatty acids, which are particularly vulnerable to free radical induced peroxidation.

- It has low reserve of anti-oxidant enzymes such as glutathione peroxidase \& catalase.

- It contains significant amount of iron deposits, despite its low iron binding capacity. Iron ions are known to stimulate free radical generation by virtue of Fenton reaction.

Lipid peroxidation is well established mechanism of cell injury in humans and used as an indicator of oxidative stress in cells and tissues. There is involvement of free radicals and lipid peroxidation in the pathophysiology of OCD. It is suspected that increased level of lipid peroxides, dialdehydes may be due to oxidation of neuronal membrane lipids by free radical. Brain nucleic acids may be metabolized to purine and nucleoside base resulting in excess of adenosine which then becomes substrate for xanthine oxidase pathways that are important in generation of free radicals. Free radicals mediated injury causes peroxidation of lipids present in cell membrane including neuronal membrane, releasing dialdehydes eg. Malondialdehyde. The involvement of free radicals in the pathophysiology of OCD is reflected by rise in the levels of serum malondialdehyde, which is one of the parameters of the study. As a defense mechanism endogenous antioxidant reduced glutathione (GSH) clears up the free radicals leading reduced circulating levels of blood GSH.

\section{Results}

The collected data was analysed by applying paired t test and coefficient of correlation analysed for the parameters MDA and reduced glutathione levels. $\mathrm{P}$-value less than $0.05(\mathrm{P}<0.05)$ was considered to be statistically significant $(\mathrm{S})$. $\mathrm{P}$-value less than $0.001(\mathrm{P}<0.001)$ was considered to be statistically highly significant (HS). P-value more than $0.05(\mathrm{P}>0.05)$ was considered to be statistically non-significant (NS) (Table 4).

The average age of subjects in controls is 34.03 years and 34.5 years in patients with OCD, which shows that mean age is nearly equal in controls and cases. Sex distribution in controls 17 males and 13 females and in patients with OCD 16 males and 14 females, which shows that sex ratio is nearly equal in controls and cases (Figures 10-14, Tables 5 and 6).

There is significant rise in serum MDA level in OCD cases as compared to the control group ( $\mathrm{p}$ value is $0.0000000653 \mathrm{i}$.e $<0.05$ ). There is significant decrease in blood levels of reduced glutathione (GSH) in OCD cases as compared to control group ( $\mathrm{p}$ value 0.000000437 i.e $<0.05$ ). The Correlation coefficient (CC) between serum MDA levels and blood levels of GSH is - 0.081 (negative). Its 95\% Confidence interval is -0.28 to 0.42 . Since the value is negative and within the range of confidence interval depicting that parameters MDA and GSH are inversely related i.e extent of rise in MDA levels causes proportional decrease in GSH levels.

\begin{tabular}{|l|c|c|}
\hline & Cases & Controls \\
\hline Mean age \pm SD (years) & $34.5 \pm 9.26$ & $34.03 \pm 8.52$ \\
\hline Sex & $16 \mathrm{M} / 14 \mathrm{~F}$ & $17 \mathrm{M} / 13 \mathrm{~F}$ \\
\hline
\end{tabular}

Table 4: Baseline characteristics of patients.

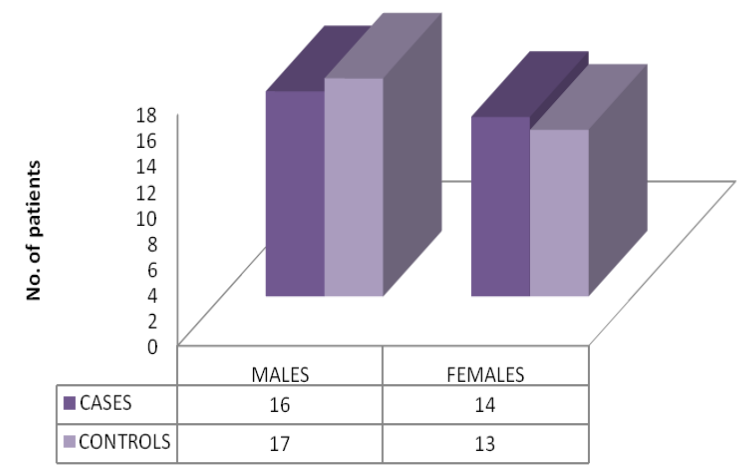

Figure 10: Bar Diagram showing sex wise distribution in cases and controls.

Mean age

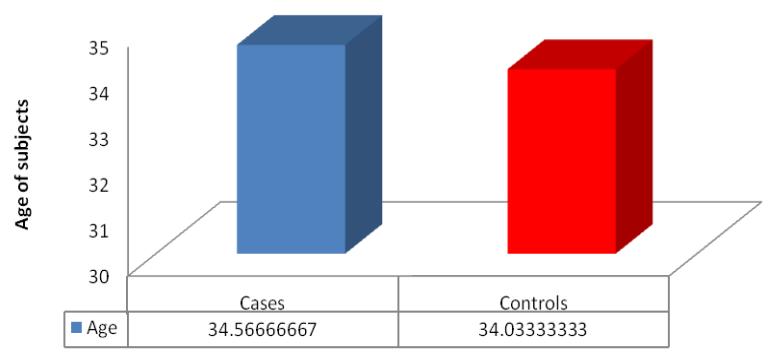

Figure 11: Bar diagram showing mean age distribution between cases and controls.

\section{GSH Mean}

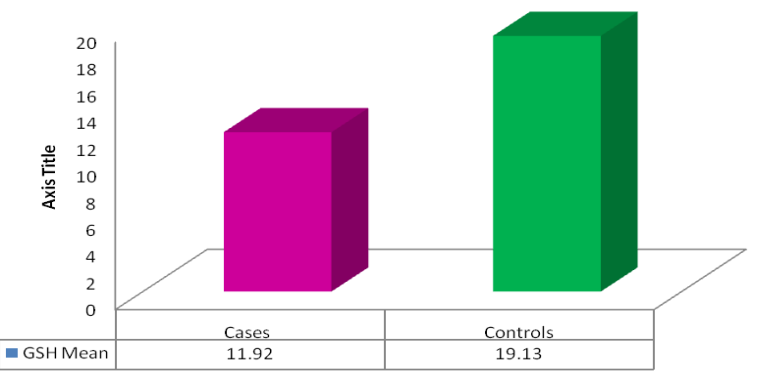

Figure 12: Bar diagram showing mean value of blood GSH levels between cases and controls.

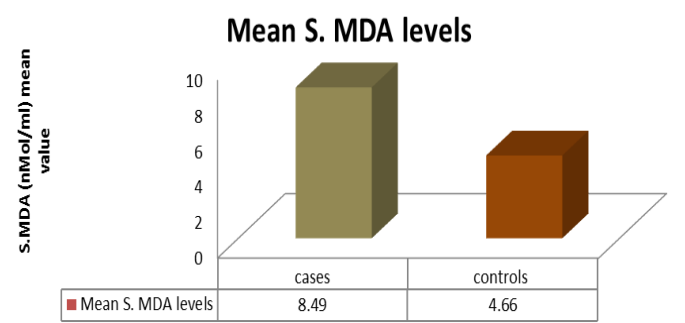

Figure 13: Bar diagram showing mean value of serum MDA levels. 


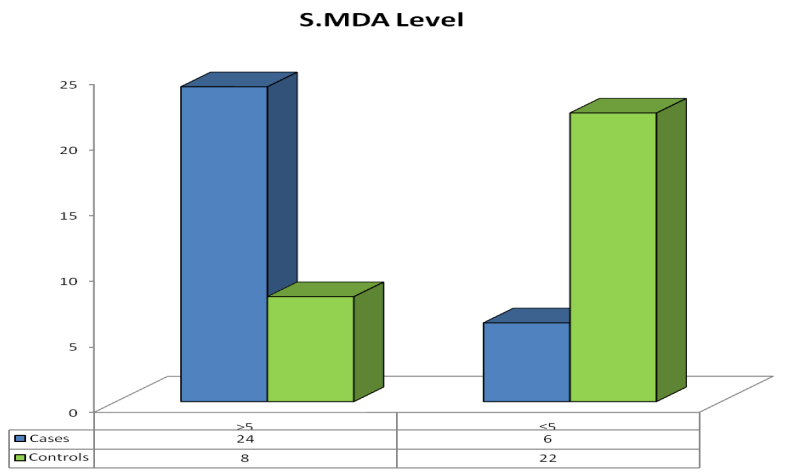

Figure 14: Bar diagram showing number of cases having serum MDA levels $>5 \mathrm{nmol} / \mathrm{ml}$.

\begin{tabular}{|l|c|c|}
\hline Group & Blood GSH levels mg/d Mean & p value \\
\hline Cases & $11.92 \pm 6.74$ & $<0.05$ \\
\hline Controls & $19.13 \pm 4.17$ & \\
\hline
\end{tabular}

Table 5: Comparison of blood levels of reduced glutathione (GSH) in OCD cases and controls.

\begin{tabular}{|l|l|l|}
\hline Group & $\begin{array}{l}\text { Serum MDA levels } \mathrm{nmol} / \mathrm{ml} \\
\text { Mean } \pm \text { SD }\end{array}$ & p value \\
\hline Cases & $8.49 \pm 3.39$ & $<0.05$ \\
\hline Controls & $4.666 \pm 1.30$ & \\
\hline
\end{tabular}

Table 6: Comparison of serum MDA levels in OCD cases and controls.

Hence the present study proves,

- $\quad$ Statistically significant rise in serum MDA levels in cases with respect to controls

- Statistically significant decrease in blood GSH levels in cases with respect to controls

- The existence of negative correlation between MDA and GSH in cases.

\section{Acknowledgement}

I owe my heartfelt thanks to Dr Vasudeo Paralikar, renowned Psychiatrist and Dr Ajit P Bhale Associate Prof Biochemistry for supporting my study.

\section{References}

1. Sadock BJ, Sadock VA, Ruiz P (2009) Chapter 14: Anxiety disorders: Obsessive compulsive disorder. Kaplan and Sadock's Comprehensive Textbook of Psychiatry. (9thedn) Volume 2. Lippincot William and Walkins.
2. Berrios GE (1989) Obsessive-compulsive disorder: its conceptual history in France during the 19th century. Compr Psychiatry 30: 283-295.

3. Jaisoorya TS, Janardhan Reddy YC, Srinath S (2003) The relationship of obsessive-compulsive disorder to putative spectrum disorders: results from an Indian study. Comprehensive Psychiatry 44: 317-323.

4. Ganong WF Chapter 7: Neurotransmitters and neuromodulators. Barrett KE Susan MB,Boitano S, Brooks HL. Review of medical Physiology (23rd edn) Tata McGraw Hill education private limited.

5. Eisenhofer G, Whitley RJ, Rosano TG. Chapter 30: Catecholamines and serotonin. Burtis CA, Ashwood ER, Bruns DE. Tietz textbook of clinical chemistry and molecular diagnostics. 5th edition. Elsevier. 851-894.

6. Svenningsson P, Chergui K, Rachleff I, Flajolet M, Zhang X, et al. (2006) Alterations in 5-HT1B receptor function by p11 in depression-like states. Science 311: 77-80.

7. Murphy DL, Lesch KP (2008) Targeting the murine serotonin transporter: insights into human neurobiology. Nat Rev Neurosci 9: 85-96.

8. Puri D (2005) Chapter 27: Free radicals in health and disease. Textbook of Biochemistry . 2nd edition. Elsevier. 716-723.

9. Bruce AF and James DC (1982) Free radicals and tissue injury laboratory investigation 17: 412-429

10. Chakraborty S, Dasgupta A, Das HN, Singh OP, Mandal AK, et al. (2009) Study of oxidative stress in obsessive compulsive disorder in response to treatment with Fluoxetine. Indian J Clin Biochem 24: 194-197.

11. Marnett LJ (1999) Lipid peroxidation-DNA damage by malondialdehyde. Mutat Res 424: 83-95.

12. Chakraborty S, Dasgupta A, Das HN, Singh OP, Mandal AK, et al. (2009) Study of oxidative stress in obsessive compulsive disorder in response to treatment with Fluoxetine. Indian J Clin Biochem 24: 194-197.

13. Shohag MH, Ullah MA, Azad MA, Islam MS, Qusar S, et al. (2012) Serum Antioxidant Vitamins and Malondialdehyde Levels in Patients with ObsessiveCompulsive Disorder. German Journal of Psychiatry 15: 10-14.

14. White CC, Viernes H, Krejsa CM, Botta D, Kavanagh TJ (2003) Fluorescencebased microtiter plate assay for glutamate-cysteine ligase activity. Analytical Biochemistry 318: 175-180.

15. Scholz RW, Graham KS, Gumpricht E, Reddy CC (1989) Mechanism of interaction of vitamin $E$ and glutathione in the protection against membrane lipid peroxidation. Ann NY AcadSci 570: 514-517.

16. Hughes RE (1964) Reduction of dehydroascorbic acid by animal tissues. Nature 203: 1068-1069

17. Ha SB, Smith AP, Howden R, Dietrich WM, Bugg S, et al. (1999) Phytochelatin synthase genes from Arabidopsis and the yeast Schizosaccharomycespombe. The Plant cell 11: 1153-1164.

18. Kumar C, Igbaria A, D'Autreaux B, Planson AG, Junot C, et al. (2011) Glutathione revisited: a vital function in iron metabolism and ancillary role in thiol-redox control. EMBO J 30: 2044-2056. 